Original Article

\title{
MOLECULAR DOCKING STUDIES ON THIADIAZOLE DERIVATIVES AS PROTEIN KINASE INHIBITORS
}

\author{
D. SIVAKUMAR ${ }^{1,2}$, G. GEETHA* \\ ${ }^{1}$ Research Scholar, Manonmaniam sundaranar University, Tirunelveli, Tamilnadu, ${ }^{2}$ PSG College of Pharmacy, Peelamedu, Coimbatore, Tamilnadu \\ Email: ggeetha97@gmail.com
}

Received: 04 Aug 2018 Revised and Accepted: 13 Nov 2018

\begin{abstract}
Objective: In the present study, a novel series of 1, 3, 4-thiadiazole derivatives were docked against the mycobacterium tuberculosis protein kinase G. 1, 3, 4-thiadiazole derivatives with a modified primary amine group at $5^{\text {th }}$ position were used for docking studies.

Methods: The three-dimensional structure of the protein was obtained from PDB, and its active sites were predicted. The structures of all the compounds were drawn using chemdraw software version 8.0. The docking studies were done by using schrödinger software against the enzyme protein kinase G. Totally eighteen compounds was synthesized based on glide score
\end{abstract}

Results: In this Docking study the thiadiazole analogues were showing good binding energy. The amino acids residues $\mathrm{GLU}_{588}, \mathrm{SER}_{412}$, GLY 410 and GLU 628 in the kinase domain active site form hydrogen bonds with the ligand.

Conclusion: The compounds $\mathrm{D}_{34}, \mathrm{D}_{16}, \mathrm{D}_{7}, \mathrm{D}_{25}, \mathrm{D}_{15}$, and $\mathrm{D}_{27}$ showed better interaction with protein kinase $\mathrm{G}(\mathrm{pknG})$ more than the other drug molecules

Keywords: Thiadiazole derivatives, molecular docking, Schroodinger software, ligand binding energy, protein kinase G enzyme, mycobacterium tuberculosis

(C) 2018 The Authors. Published by Innovare Academic Sciences Pvt Ltd. This is an open-access article under the CC BY license (http://creativecommons.org/licenses/by/4.0/) DOI: http://dx.doi.org/10.22159/ijpps.2018v10i12.28948

\section{INTRODUCTION}

Mycobacterium tuberculosis (MTB) is an aerobic pathogenic bacteria and is the causative agent of most cases of tuberculosis Tuberculosis (TB) is a lung infection and is highly contagious and deadly disease. The reason for the widespread of this disease is the emergence of multi-drug resistant TB strains and less availability of a new drug with a novel mechanism of action [1].

A permanent solution to this disease will be the development of vaccines. But the most reliable will be chemotherapy, which requires effective and non-toxic antitubercular agents. The identification of new target sites will decrease the problems associated with multidrug resistant strains, for this biochemical pathway specific to the mycobacterium disease cycle must be better understood [2]

This strategy and the conditions have indulged in the development of new thiadiazole moieties as antitubercular drugs by inhibiting the important enzymes involved in the bacterial life cycle. The enzyme protein kinase G (PKnG) is not needed for mycobacteria growth, but this enzyme is very much important for the survival of Mycobacterium in the host macrophages [3] and has marked as the best target enzyme protein for docking studies. Different 134 thiadiazole derivatives are considered as ligands or drug molecules which are going to interact with the enzyme thus inhibiting its activity [4].

Pathogenecity of mycobacteria is due to its survival in host cell macrophages. All phagocytosized microbes are rapidly transferred from host cell macrophages to lysosomes and degraded. Mycobacteria resist lysosomal delivery and also reuptake into macrophages, so they survive intracellularly. This is due to protein kinase G secreted from mycobacteria which inhibit macrophages lysosome fusion causing the survival of the bacteria. Chemical inhibition of protein kinase $\mathrm{G}$ causes lysosomal localization and mycobacterial cell death [5]. This enzyme inhibition is done by drug molecules or ligands binding with the enzymes. The binding capacity of the ligand with the enzyme was analysed by docking studies. The present study was carried out to evaluate the efficiency of the thiadiazole compounds against mycobacteria using molecular docking studies with the objective to find potential drug targets.

\section{MATERIALS AND METHODS}

Schrodinger software version was used for the docking studies. For the determination of protein-Ligand binding affinities and scoring function GLIDE 4.0 (Grid Based Ligand Docking with Energies) XP (Extra Precision) docking protocol was used.

\section{Ligand preparation}

The 3D structure of the ligand 1, 3, 4-thiadiazoles with calculated molecular weight from 240 and its derivatives (table 2) were drawn using chemdraw software version 8.0. The basic structure of thiadiazole was got from pubmed database. The ligand structures were constructed using the splinter dictionary of Maestro 9.4 (Schrodinger, LLC) using the Optimized Potentials for Liquid Simulations-All Atom (OPLS-AA) force field [7] with the steepest descent followed by curtailed Newton conjugate gradient protocol. Partial atomic charges were computed using the OPLS-AA force field [6].

\section{Protein/enzyme preparation}

The X-ray crystal structures protein kinase G (PDB: 2PZI) retrieved from the Research Collaboratory for Structural Bioinformatics (RCSB) Protein Data Bank was used in the present study. Water molecules of crystallization were detached from the composite, and the protein was optimized for docking using the protein preparation and refinement utility provided by Schrödinger LLC. Partial atomic charges were assigned according to the OPLS-AA force field.

\section{Bind site analysis}

Active sites or binding sites for enzymes were predicted from a pictorial database of 3D structures in the protein data bank (PDB sumàn Q-Site Finder software from university of Leeds Bioinformaticswas used for ligand binding site predictionIn that 6 sites where found active 1 for ligands and 5 for metals). So it was decided to keep all the amino acids in the active site of the enzyme [7]. 


\section{RESULTS AND DISCUSSION}

In this work, totally 40 compounds of thiadiazoles derivatives with modifications in the amino group of $5^{\text {th }}$ position were used for the study. Six targets of binding sites on the crystallographic structure of the enzyme have been examined for ligand-based docking program. The ligands are screened for their ability to dock within the active site of the enzyme. Virtual screening is not performed to find the numbers of a chemical compound which inhibit the activity of the enzyme. Instead extra precision mode (XP) were used. More negative glide score value indicates a good interaction of the ligand with the target protein. After analyzing the different docking interactions of ligands, the compounds namely D34, D16, D7, D25, D15, and D27 showed fairly better interaction with protein kinase (PknG) with the more negative G-Score value than the other drug molecules. The amino acids residues GLU588, SER412, GLY410 and GLU 628 in the kinase domain (fig. 1, 2 and 3) form hydrogen bonds with the ligands. The amino acids like serine and glutamine form hydrogen bonds with the drug molecules of $\mathrm{D}$ series.
Compound D34 which is a chalcone derivative of thiadiazole contains pyridyl group at $2^{\text {nd }}$ position (R Group) and a m-Hydroxyp-Methoxy Phenyl group at substituted at the amino group of $5^{\text {th }}$ position ( $\mathrm{R}_{1}$ position) possess high glide score value- 6.69 and glide energy value of-42.64 which shows best ligand and enzyme interaction. Also, compound D16 which contains a p-hydroxyphenyl group at $\mathrm{R}$ position and a dimethyl aminophenyl group at position R1 showed high glide score with-6.62 and glide energy of- 48.62 . Many compounds in D series showed good interaction with the enzyme, having glide score range from-4.8 to-6.69 (table 1).

Mycobacterium tuberculosis PknG is an essential receptor-like protein kinase involved in cell growth control. M. tuberculosis PKnG is a transmembrane Ser/Thr protein kinase (STPK) highly conserved in grampositive bacteria and apparently essential for viability [8].

The thiadiazole derivatives and its different analogues were found to bind with protein kinase enzyme. The docking screening was performed by employing the scoring function. The result was based on the score of estimated free energy, inhibition constant, and hydrogen bonding.

Table 1: Data of estimated docking parameters of thiadiazole analogues with protein kinase G

\begin{tabular}{|c|c|c|c|c|c|c|c|}
\hline Title & Docking score & XP G score & Glide G score & Glide energy & Glide $\mathrm{E}$ internal & xp h bond & Glide ligand efficiency [8] \\
\hline \multicolumn{8}{|l|}{$2 \mathrm{PZI}$} \\
\hline D34. mol & -6.3394 & -6.6935 & -6.6935 & -42.6465 & 0 & -2.01368 & -0.26774 \\
\hline D16. mol & -6.2503 & -6.6269 & -6.6269 & -48.6215 & 15.19324 & -0.35539 & -0.24544 \\
\hline D7. mol & -5.8741 & -6.2339 & -6.2339 & -43.7537 & 4.487678 & -0.9 & -0.25975 \\
\hline D25. mol & -5.8323 & -6.1465 & -6.1465 & -47.7566 & 8.266831 & -1.18 & -0.23641 \\
\hline D15. mol & -5.7560 & -6.1027 & -6.1027 & -42.2412 & 9.169291 & -2.85873 & -0.25428 \\
\hline D27. mol & -5.673 & -6.246 & -6.2463 & -43.7829 & 10.34215 & -0.9975 & -0.26026 \\
\hline D33. mol & -5.4844 & -5.9822 & -5.9822 & -41.3284 & 11.96712 & -1.95 & -0.2601 \\
\hline D17. mol & -5.3738 & -5.7475 & -5.7475 & -41.0715 & 7.604469 & -0.7 & -0.2299 \\
\hline D14. mol & -5.0956 & -5.4423 & -5.4423 & -47.0438 & 0 & -1.51683 & -0.20932 \\
\hline D26. mol & -5.0464 & -5.3673 & -5.3673 & -47.2284 & 13.75001 & -0.7 & -0.20644 \\
\hline D10. mol & -4.9576 & -5.2905 & -5.2905 & -40.19 & 7.479155 & -0.29881 & -0.23002 \\
\hline D39. mol & -4.8320 & -5.1939 & -5.1939 & -41.3978 & 12.04666 & 0 & -0.22583 \\
\hline D36. mol & -4.7932 & -5.2721 & -5.2721 & -41.488 & 3.481447 & -0.23762 & -0.22923 \\
\hline D9. mol & -4.6992 & -5.0539 & -5.0539 & -41.6236 & 0 & -0.68761 & -0.21974 \\
\hline D30. mol & -4.6905 & -5.0047 & -5.0047 & -41.2029 & 5.028046 & -0.05378 & -0.20853 \\
\hline D24. mol & -4.5593 & -5.1842 & -5.1842 & -43.8498 & 17.06249 & -0.7 & -0.23565 \\
\hline D28. $\mathrm{mol}$ & -4.5470 & -4.8612 & -4.8612 & -42.9364 & 9.682065 & 0 & -0.20255 \\
\hline D8. mol & -4.5356 & -4.8685 & -4.8685 & -41.0375 & 9.210653 & -0.49952 & -0.21168 \\
\hline D29. $\mathrm{mol}$ & -4.4410 & -5.0136 & -5.0136 & -42.2539 & 6.16229 & -1.37057 & -0.2089 \\
\hline D21. mol & -4.3420 & -4.6562 & -4.6562 & -40.4049 & 7.941264 & -1.03888 & -0.20245 \\
\hline D2. mol & -4.3106 & -4.6435 & -4.6435 & -43.1724 & 8.176312 & 0 & -0.19348 \\
\hline D22. mol & -4.2770 & -4.5912 & -4.591 & -41.656 & 11.264 & -0.6537 & -0.1836 \\
\hline D5. mol & -4.2158 & -4.4479 & -4.4479 & -40.1022 & 4.208613 & -0.7 & -0.21181 \\
\hline D32. $\mathrm{mol}$ & -4.1778 & -4.5397 & -4.5397 & -43.5986 & 8.83195 & -0.07374 & -0.18916 \\
\hline D12. mol & -4.1573 & -4.466 & -4.46 & -44.3128 & 7.143773 & -0.56692 & -0.17864 \\
\hline D40. mol & -4.1241 & -4.8366 & -4.83667 & -36.6305 & 9.555526 & -0.45638 & -0.23032 \\
\hline D38. mol & -4.1169 & -4.5018 & -4.50183 & -43.3633 & 8.564388 & -0.2938 & -0.19573 \\
\hline D13. mol & -4.0203 & -4.6467 & -4.64677 & -41.3201 & 11.99485 & -0.89203 & -0.21122 \\
\hline D1. mol & -3.9445 & -4.2774 & -4.27743 & -33.6689 & 13.21224 & -0.084 & -0.19443 \\
\hline D31. mol & -3.9302 & -4.3940 & -4.39404 & -27.7501 & 13.77523 & -0.39136 & -0.19973 \\
\hline D6. mol & -3.9295 & -4.2924 & -4.29247 & -42.914 & 11.81976 & 0 & -0.1651 \\
\hline D3. mol & -3.9106 & -4.2142 & -4.21422 & -41.3832 & 4.710607 & -0.65721 & -0.18323 \\
\hline D35. mol & -3.8009 & -4.1932 & -4.19328 & -45.9145 & 6.055371 & -0.7 & -0.16773 \\
\hline D23. $\mathrm{mol}$ & -3.7838 & -4.0980 & -4.09804 & -39.1289 & 6.106972 & -1.31092 & -0.17075 \\
\hline D4. mol & -3.7459 & -4.2672 & -4.26725 & -46.0125 & 11.90417 & -1.99717 & -0.17069 \\
\hline D18. mol & -3.6395 & -3.9862 & -3.98628 & -46.2679 & 3.122691 & -1.04324 & -0.1661 \\
\hline D11. mol & -3.5951 & -4.1160 & -4.11603 & -48.3259 & 9.010351 & -0.35 & -0.15245 \\
\hline D19. mol & -3.2861 & -3.6328 & -3.63287 & -36.1451 & 0.670452 & -0.32319 & -0.15137 \\
\hline D37. mol & -3.1718 & -3.5337 & -3.53376 & -41.5995 & 7.738014 & -1.4114 & -0.15364 \\
\hline D20. $\mathrm{mol}$ & -2.1184 & -2.4651 & -2.46517 & -43.0892 & 10.58537 & 0 & -0.10272 \\
\hline
\end{tabular}

General structure of compound D-Series

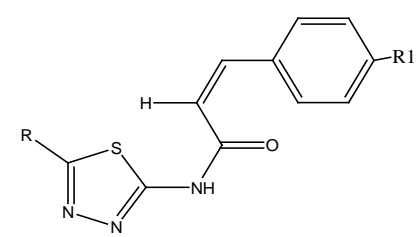


Table 2: 134 thiadiazole derivatives of D-series

\begin{tabular}{|c|c|c|c|}
\hline Compound code & $\mathbf{R}$ & R1 & \\
\hline \multirow[t]{10}{*}{ D1-D10 } & $\mathrm{C}_{6} \mathrm{H}_{5}$-phenyl & D1 & Phenyl \\
\hline & & $\mathrm{D} 2$ & 4-methoxy phenyl \\
\hline & & D3 & 2-hydroxy phenyl \\
\hline & & D4 & 3-hydroxy-4-methoxy phenyl \\
\hline & & D5 & Furfuryl \\
\hline & & D6 & p-dimethyl amino phenyl \\
\hline & & D7 & 2-amino phenyl \\
\hline & & D8 & 3-amino phenyl \\
\hline & & D9 & 4-amino phenyl \\
\hline & & D10 & 4-hydroxy phenyl \\
\hline \multirow[t]{10}{*}{ D11-D20 } & 4-Hydroxyl phenyl & D11 & Phenyl \\
\hline & & D12 & 4-methoxy phenyl \\
\hline & & D13 & 2-hydroxy phenyl \\
\hline & & D14 & 3-hydroxy-4-methoxy phenyl \\
\hline & & D15 & Furfuryl \\
\hline & & D16 & p-dimethyl amino phenyl \\
\hline & & D17 & 2-amino phenyl \\
\hline & & D18 & 3-amino phenyl \\
\hline & & D19 & 4-amino phenyl \\
\hline & & D20 & 4-hydroxy phenyl \\
\hline \multirow[t]{11}{*}{ D21-D30 } & 2-Hydroxy Phenyl & D21 & Phenyl \\
\hline & & D22 & 4-methoxy phenyl \\
\hline & & D23 & 2-hydroxy phenyl \\
\hline & & D24 & 3-hydroxy-4-methoxy phenyl \\
\hline & & D25 & Furfuryl \\
\hline & & D26 & p-dimethyl amino phenyl \\
\hline & & $\mathrm{D} 27$ & 2-amino phenyl \\
\hline & & D28 & 3-amino phenyl \\
\hline & & D29 & 4-amino phenyl \\
\hline & & D30 & 4-hydroxy phenyl \\
\hline & Pyridyl & D31 & Phenyl \\
\hline \multirow[t]{9}{*}{ D31-D40 } & & D32 & 4-methoxy phenyl \\
\hline & & D33 & 2-hydroxy phenyl \\
\hline & & D34 & 3-hydroxy-4-methoxy phenyl \\
\hline & & D35 & Furfuryl \\
\hline & & D36 & p-dimethyl amino phenyl \\
\hline & & D37 & 2-amino phenyl \\
\hline & & D38 & 3-amino phenyl \\
\hline & & D39 & 4-amino phenyl \\
\hline & & $\mathrm{D} 40$ & 4-hydroxy phenyl \\
\hline
\end{tabular}

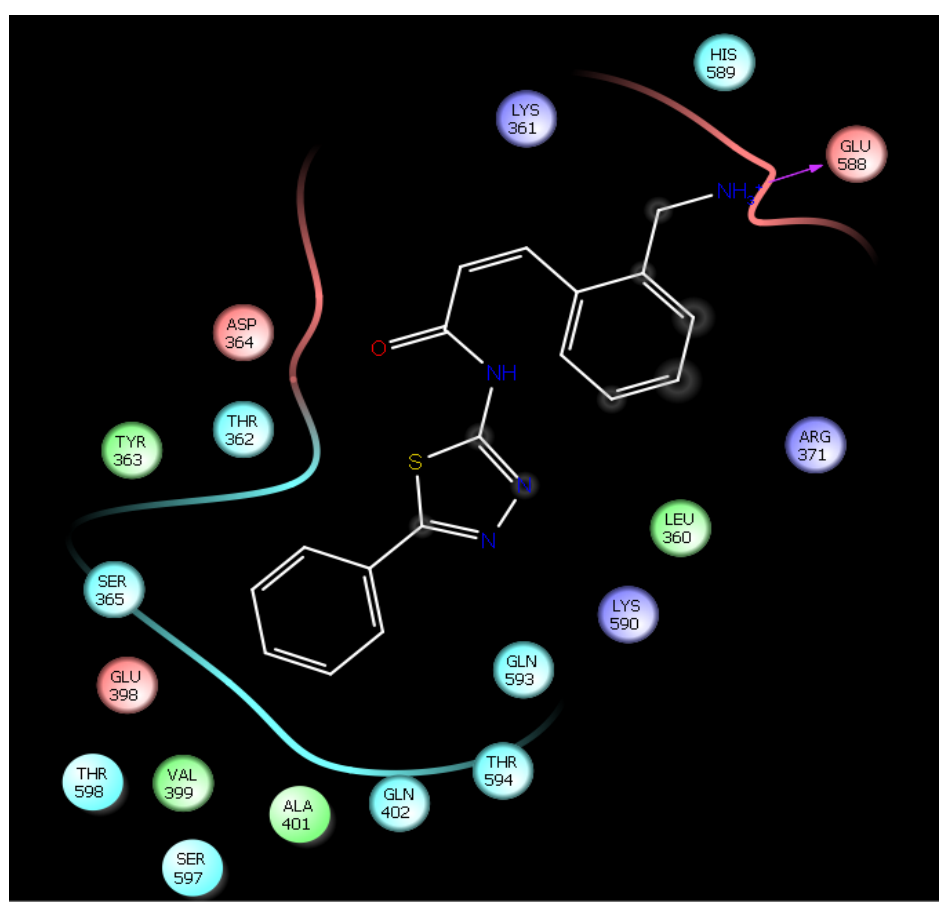

Fig. 1: Interaction of the compound D7 with the enzyme 


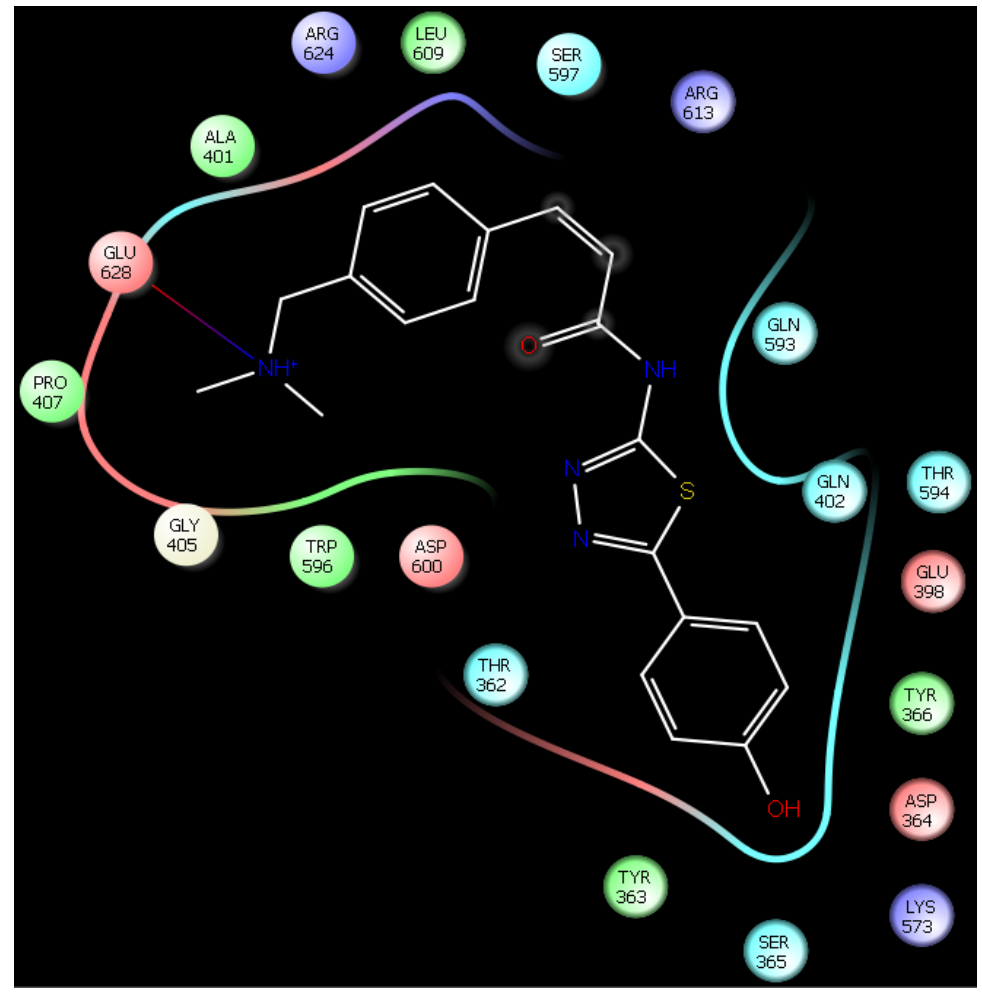

Fig. 2: Interaction of compound D16 with the enzyme

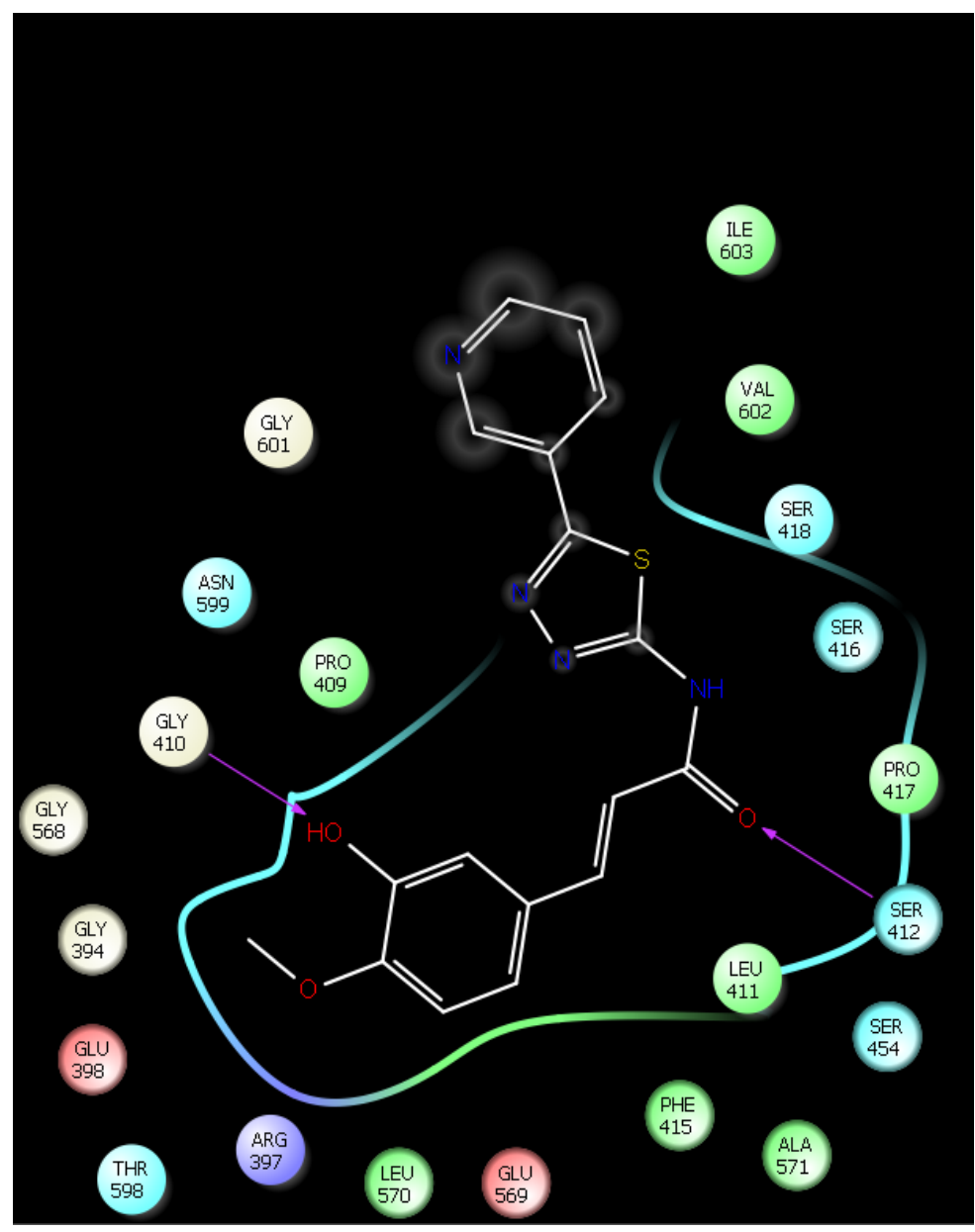

Fig. 3: Interaction of compound D34 with the enzyme 


\section{CONCLUSION}

On comparing the glide score values, the better interaction was shown by compounds $\mathrm{D}_{34}, \mathrm{D}_{16}, \mathrm{D}_{7}$, and $\mathrm{D}_{25}$ with glide score values$6.69,-6.62,-6.23$ and -6.14 respectively. Thus by analyzing these datas 134 thiadiazole derivatives can be considered as a potent inhibitor against the enzyme protein kinase in Mycobacterium tuberculosis.

\section{ACKNOWLEDGMENT}

The First authors thank PSG College of pharmacy, peelamedu, coimbatore for providing experimental support.

\section{AUTHORS CONTRIBUTIONS}

All the experimental work was carried out by the first author, whereas, the second author, supervised them.

\section{CONFLICT OF INTERESTS}

Declared none

\section{REFERENCES}

1. Abdella G, Mirutse G, Adane W, Gobena A. In vitro antimycobacterial activity of selected medicinal plants against mycobacterium tuberculosis and mycobacterium bovis strains. BMC Complementary Alternative Med 2013;13:1-6.
2. Neetu Kumari T, Jaya Sivaswami T. Resazurin reduction assays for screening of anti-tubercular compounds against dormant and actively growing mycobacterium tuberculosis, mycobacterium bovis BCG and mycobacterium smegmatis. J Antimicrob Chemother 2007;60:288-93.

3. Ahmet Ilmaz Coban. A new rapid colorimetric method for testing Mycobacterium tuberculosis susceptibility to isoniazid and rifampicin: a crystal violet decolourisation assay. Mem Institute Oswaldo Cruz, Rio de Janeiro 2014;109:246-9.

4. Sunil S, Sachin Sharma, Sharma SK, Meharwal SK, Jindal SK, Meera Sharma. Drug susceptibility of Mycobacterium tuberculosis to primary antitubercular drugs by nitrate reductase assay. Indian J Med Res 2004;120:468-71.

5. Santhi N, Aiswarya S. Insights from the molecular docking of withanolide derivatives to the target protein PknG from Mycobacterium tuberculosis. Bioinformation 2011;7:1-5.

6. Borappa Muthukala, Kanakarajan Sivakumari, Kamalanathan Ashok. In silico docking of quercetin compound against the hela cell line proteins. Int J Curr Pharm Res 2015;7:13-6.

7. Vanitha Varadharaj, Naresh Kandakatla. Glycogen synthase kinase- 3 beta protein inhibition by selected phytocompounds in silico. Asian J Pharm Clin Res 2017;10:87-90.

8. Smruthi G, Mahadevan V, Vadivel V, Brindha P. Docking studies on antidiabetic molecular targets of phytochemical compounds of syzygium cumini (1.) skeels. Asian J Pharm Clin Res 2016;9:287-93. 